\section{Schritt für Schritt zum ePaper}

Schritt 1: Wenn Sie bei SpringerPflege.de noch keinen Account haben, müssen Sie sich zunächst unter www.springerpflege.de/ register anmelden. Wenn Sie schon einen Zugang haben, loggen Sie sich bitte ein und gehen direkt zu Schritt 2.

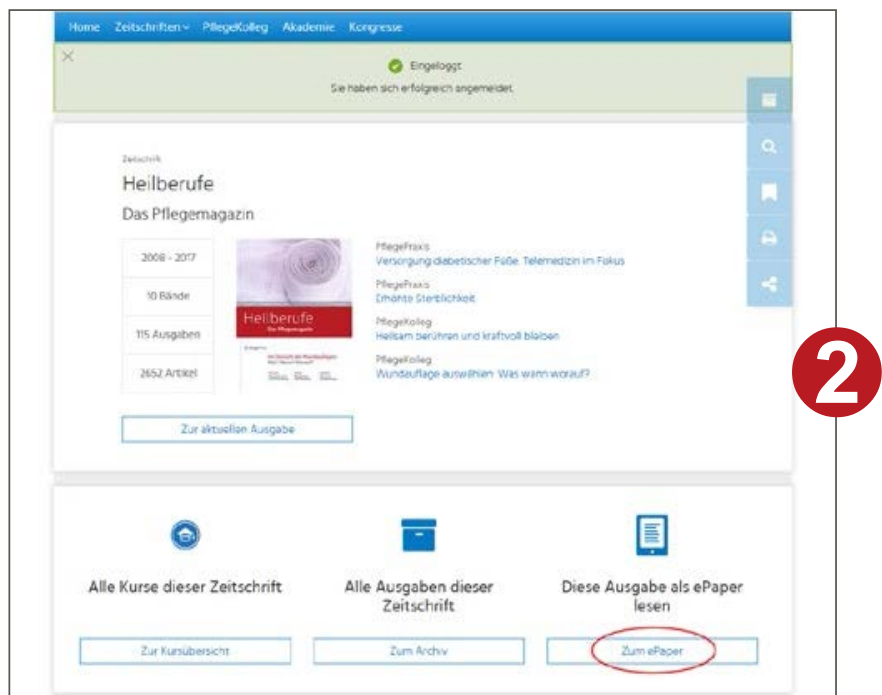

Schritt 3: Das ePaper öffnet sich in einem neuen Fenster. Über die Pfeiltasten oder durch Ziehen mit der Maus blättern Sie durch die Ausgabe. Wenn Sie mobil unterwegs sind, können Sie mit einem Wischen nach rechts oder links die Seiten umblättern. Mit einem Doppelklick auf den gewünschten Text wird dieser herangezoomt. Suchen Sie einen bestimmten Beitrag im Heft, können Sie in der Suchmaske Schlagwörter eingeben oder durch Klicken im interaktiven Inhaltsverzeichnis sofort auf der richtigen Seite landen. Eine Übersicht aller Seiten bietet der Button „Thumbnails“. Auf Smartphone und Tablet finden Sie diese Möglichkeiten durch einen Klick auf den Menu-Button.

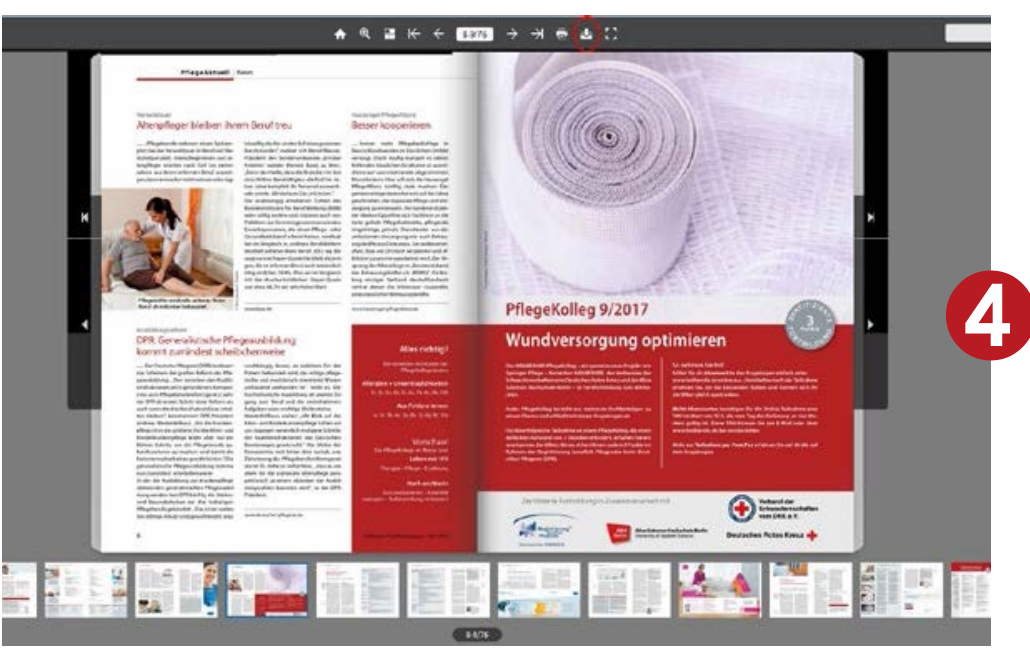

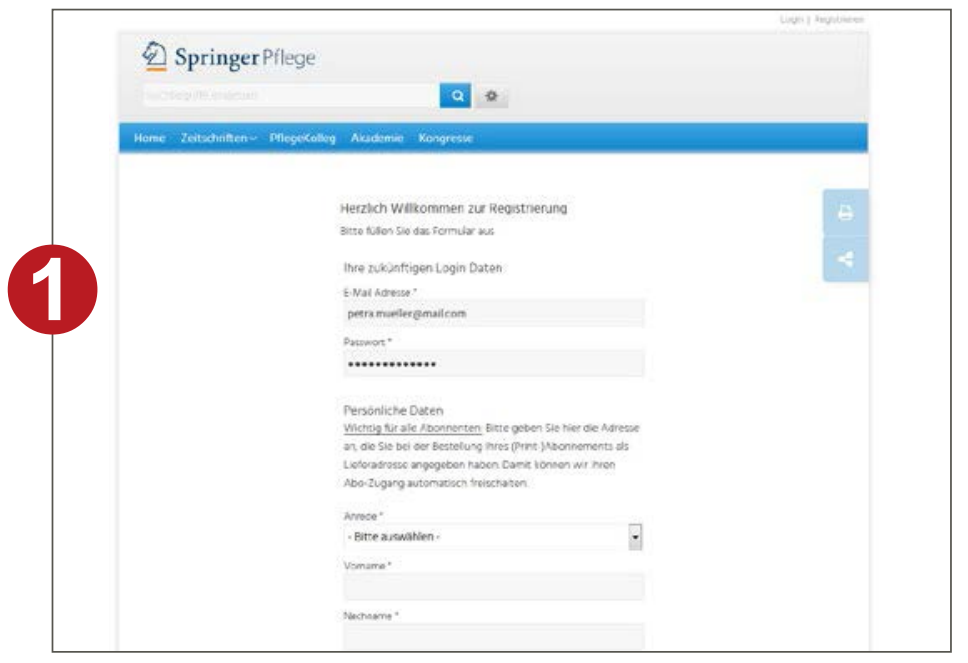

Schritt 2: Navigieren Sie zur Startseite von HEILBERUFE, www.springerpflege.de/heilberufe/10661680. Dort erscheint die aktuelle Ausgabe der Zeitschrift. Als eingeloggter User sehen Sie unten rechts den Button „Zum ePaper“. Auf dieser Seite können Sie außerdem im Archiv nach älteren Heften suchen.

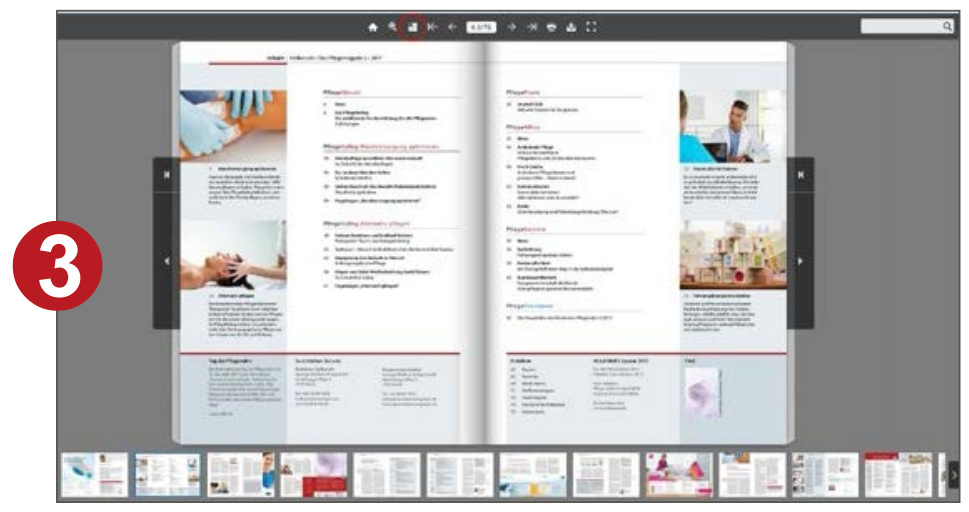

Schritt 4: Auch unterwegs, im Urlaub oder im Flugzeug ohne Internetverbindung können Sie Ihre digitale HEILBERUFE durchblättern: Laden Sie dazu das ePaper über das Symbol „Download“ in der Navigationsleiste oben direkt auf Ihr Gerät. Damit haben Sie eine oder auch mehrere Ausgaben Ihrer Zeitschrift jederzeit offline abrufbar. 